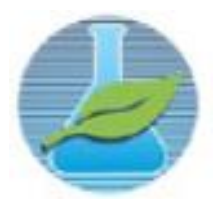

JCEC/REQ ${ }^{2}$

Journal

ISSN: 2446-9416

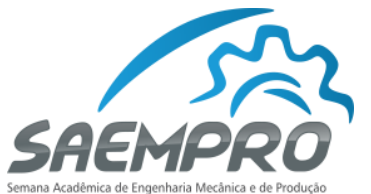

\author{
"EU, A INDÚSTRIA E O MUNDO" \\ 08 a 11 de novembro de 2016 no campus Viçosa da UFV \\ Departamento de Engenharia de Produção e Mecânica - DEP \\ Universidade Federal de Viçosa - UFV
}

\title{
AVALIAÇÃO DA DELAMINAÇÃO NA FURAÇÃO DE MATERIAIS COMPÓSITOS REFORÇADOS COM FIBRAS DE CARBONO
}

\author{
Larissa Maria da Silva \\ Universidade Federal de Viçosa, Departamento de Engenharia de Produção e Mecânica \\ $\mathrm{Ph}$. Rolfs s/n - 36570-000 - Viçosa - MG \\ larissa.maria@ufv.br
}

\section{INTRODUÇÃO}

Materiais compósitos são formados pela união de dois ou mais materiais com características distintas para formar um terceiro com características combinadas. Esses materiais são largamente utilizados na fabricação de peças otimizadas em que a redução de massa é necessária.

Os compósitos são fabricados a partir de moldes. Um compósito laminado é constituído de fibras ou laminas despostas em camadas imersas na fase continua denominada matriz. As fibras são responsáveis pela resistência mecânica do material enquanto a matriz serve para manter as fibras unidas no formato desejado.

A furação é a operação de usinagem mais comum utilizada no acabamento dessas peças, mas comumente provoca defeitos no material. Um desses defeitos é a dissociação das lâminas de tecido, chamado de delaminação. A delaminação cria pontos de concentração de tensão, por isso deve ser controlada.

\section{OBJETIVO}

Este trabalho tem como objetivo quantificar o nível de defeitos resultantes da furação de compósitos reforçados com fibra de carbono ou com fibra de aramida e associar esse comportamento às características do material.

\section{MATERIAIS E MÉTODOS}

Os corpos de prova utilizados foram 3 placas formadas por 5 camadas de tecido tipo twill de fibra de carbono e de 3 placas formadas de 5 camadas de tecido tipo twill de fibra de Kevlar® (aramida), todas imersas numa matriz de resina Epóxi Araldite LY5052 e Endurecedor Aradur 5052 CH na proporção 100/38 em massa.

O ensaio de furação consistiu na realização de 5 furos para cada uma das rotações da fresadora. As rotações variaram de $1500 \mathrm{rpm}$ a $5000 \mathrm{rpm}$. Os furos foram feitos na fresadora ferramenteira FVF 3000/3000 Vs, com broca convencional haste cilíndrica fabricada em aço rápido com $5 \mathrm{~mm}$ de diâmetro. Os furos foram espaçados de aproximadamente $1 \mathrm{~cm}$. A velocidade da mesa utilizada foi de $350 \mathrm{~mm} / \mathrm{min}$. Não houve variação do avanço. Cada peça foi ensaiada em duas rotações distintas, totalizando 10 furos.

As peças foram fotografadas numa impressora com a resolução de 600 dpi (pontos por polegada), colorida e guardadas em formato .bmp, sem o pré processamento da imagem.

O processamento das imagens no software Matlab® converteu-as para imagens binárias, em preto e branco. Em seguida cada furo foi cortado no Paint ${ }^{\circledR}$, e salvo em formato .bmp com 24 bits 
de resolução. A contagem de pixels brancos foi feita individualmente em cada furo no software Matlab®. A área em branco corresponde a área de delaminação dos furos.

\section{RESULTADOS}

O treshold mais adequado para as placas de Kevlar foi de 0.75 e para as placas de fibra de carbono foi de 0.30. As imagens digitalizadas e processadas dos furos das placas são apresentadas a seguir:

Tabela 1 - Imagens digitalizadas e processadas dos furos das placas de Kevlar submetidas ao teste de furação.

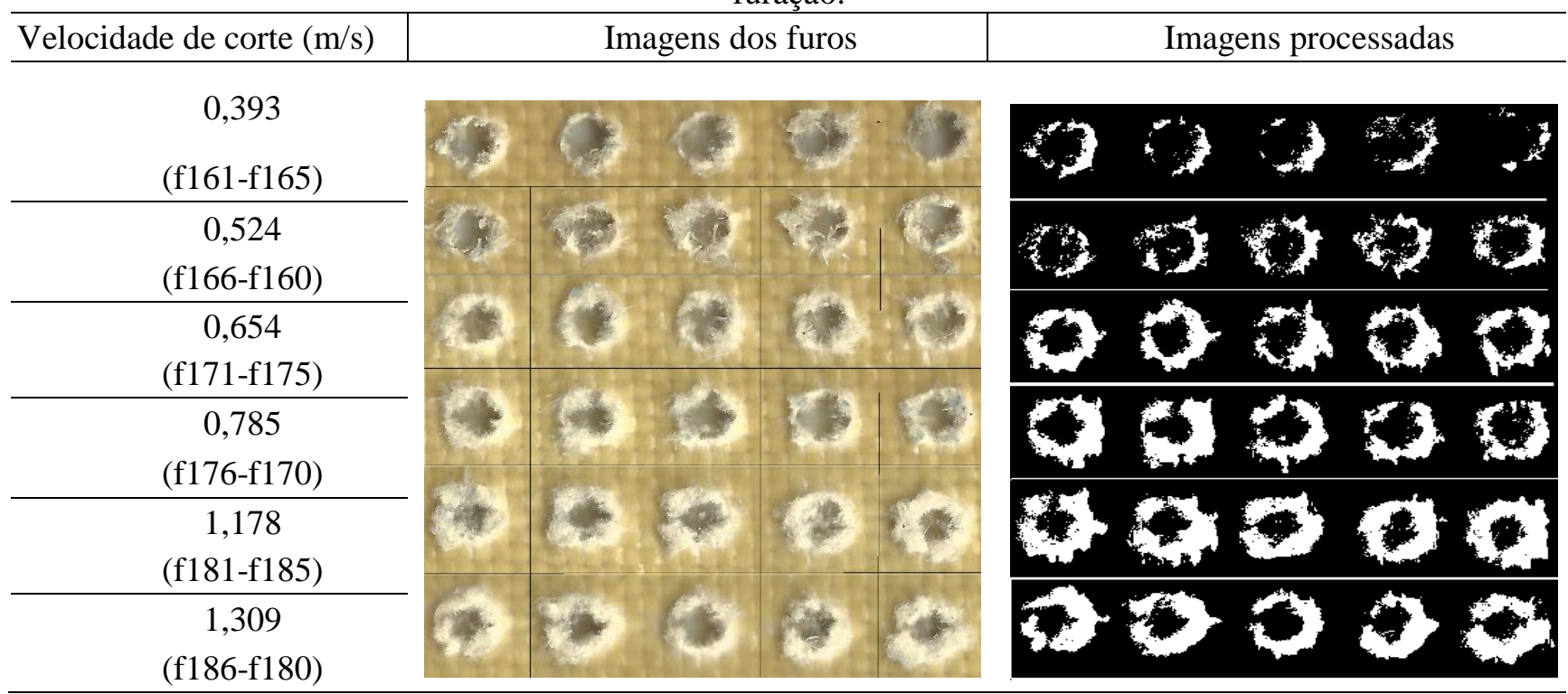

Tabela 2 - Imagens digitalizadas e processadas dos furos das placas de fibra de carbono submetidas ao teste de furação.

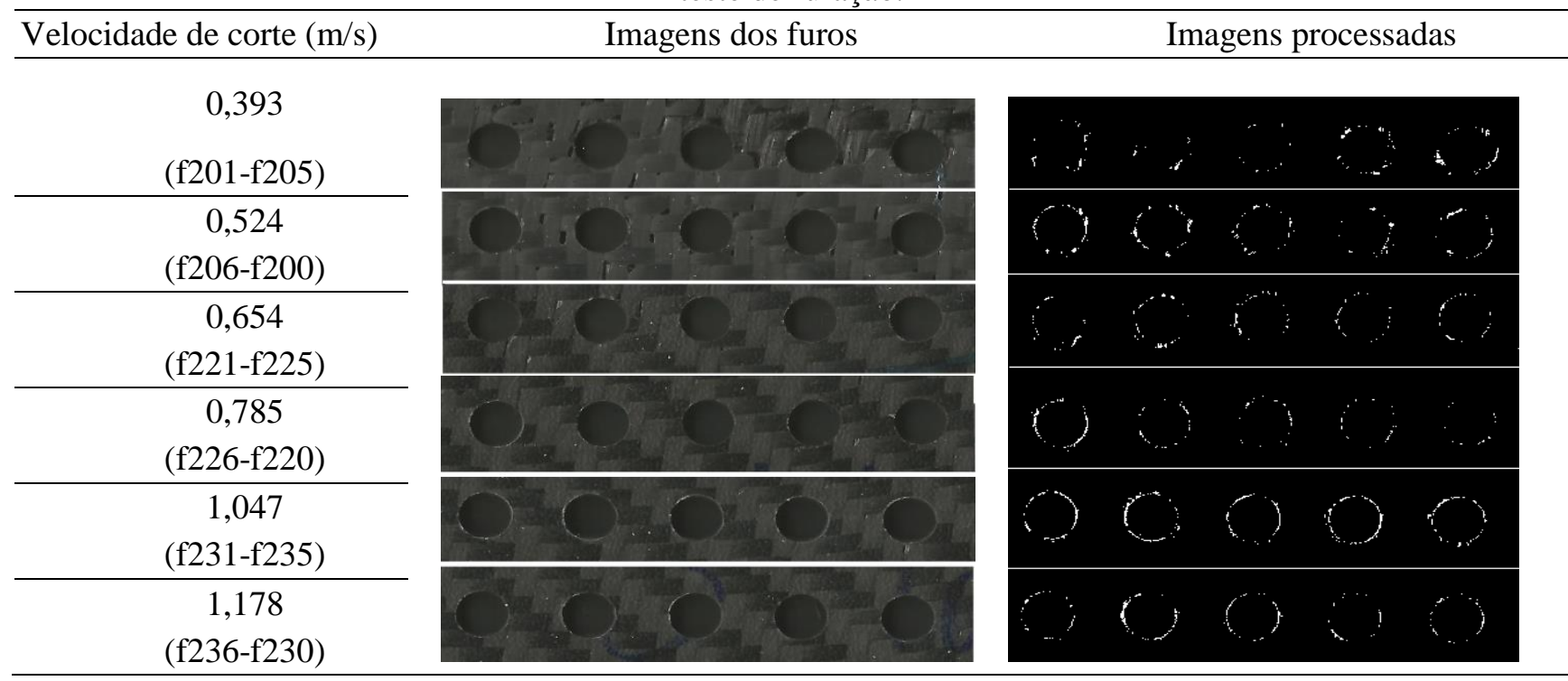

A área delaminada média para cada velocidade de corte da fresadora é:

Tabela 3 - Delaminação média do ensaio de furação da placa de fibra de kevlar. 


\begin{tabular}{ccc}
\hline Velocidade de corte $(\mathrm{m} / \mathrm{s})$ & Área Média Delaminada $\left(\mathrm{m}^{2}\right)$ & Desvio padrão $\left(\mathrm{m}^{2}\right)$ \\
\hline 0,397 & $7,617 \cdot 10^{-6}$ & $2,452 \cdot 10^{-6}$ \\
0,523 & $11,819 \cdot 10^{-6}$ & $2,346 \cdot 10^{-6}$ \\
0,654 & $19,743 \cdot 10^{-6}$ & $1,637 \cdot 10^{-6}$ \\
0,785 & $22,674 \cdot 10^{-6}$ & $4,868 \cdot 10^{-6}$ \\
1,178 & $24,916 \cdot 10^{-6}$ & $3,618 \cdot 10^{-6}$ \\
1,309 & $30,193 \cdot 10^{-6}$ & $2,133 \cdot 10^{-6}$ \\
\hline
\end{tabular}

Tabela 4 - Delaminação média do ensaio de furação das placas de fibra de carbono.

\begin{tabular}{ccc}
\hline Velocidade de corte $(\mathrm{m} / \mathrm{s})$ & Área Média Delaminada $\left(\mathrm{m}^{2}\right)$ & Desvio padrão $\left(\mathrm{m}^{2}\right)$ \\
\hline 0,397 & $1,038 \cdot 10^{-6}$ & $0,377 \cdot 10^{-6}$ \\
0,523 & $0,63 \cdot 10^{-6}$ & $0,481 \cdot 10^{-6}$ \\
0,654 & $0,834 \cdot 10^{-6}$ & $0,545 \cdot 10^{-6}$ \\
0,785 & $0,563 \cdot 10^{-6}$ & $0,239 \cdot 10^{-6}$ \\
1,047 & $1,658 \cdot 10^{-6}$ & $0,232 \cdot 10^{-6}$ \\
1,178 & $1,073 \cdot 10^{-6}$ & $0,421 \cdot 10^{-6}$ \\
\hline
\end{tabular}

\section{CONCLUSÃO}

No teste de furação dos compósitos é possível identificar que a medida que a velocidade de corte aumenta, a peça de kevlar delamina mais. Contudo para a peça de fibra de carbono esta relação não pôde ser observada. Em velocidades de corte entre $0,393 \mathrm{~m} / \mathrm{s}$ e $0,785 \mathrm{~m} / \mathrm{s}$ não houve diferença significativa entre a quantidade de delaminação nas peças.

Ocorre que os dois materiais delaminam de maneiras diferentes. Enquanto a fibra de Kevlar desfia como linhas de um tecido, a de carbono quebra em pequenas lascas. Isso faz o acabamento da peça de carbono ter melhor qualidade, e minimizar os efeitos prejudiciais da delaminação.

O compósito de kevlar é um material tenaz, portanto não quebra facilmente, mas desfia comprometendo o acabamento. Vale lembrar que o desfiamento do tecido pode ter um potencial de melhorar o ajuste das peças, funcionando como uma bucha para absorver impactos nas uniões.

\section{REFERÊNCIAS}

CALLISTER,William D. Jr.; "Ciência e Engenharia de Materiais: Uma Introdução"; 5 ed; Rio de Janeiro; 2002.

ASKLAND, D.R.; Phulé. P.P.; "Ciência e engenharias de materiais”; CENGAGE Learning; São Paulo; 2008; Cap. 17.

RUBIO, J.C.C.; Abrão, A.M.; Faria, P. E.; Davim, J. P.; “Análise digital de danos em furação de materiais compósitos laminados", Ciência e Tecnologia dos Materiais [online], Vol.19, nº 1/2, pp. 19-24. ISSN 0870-8312. Lisboa, janeiro de 2007. 